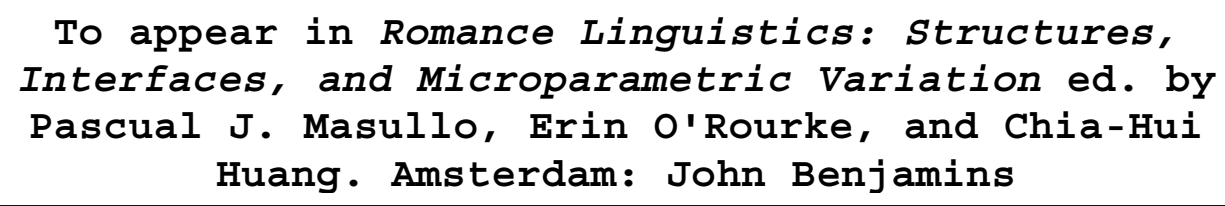

\title{
RHOTIC METATHESIS ASYMMETRIES IN ROMANCE FORMALIZING THE EFFECTS OF ARTICULATION AND PERCEPTION ON SOUND CHANGE*
}

\author{
ERIC RUSSELL WEBB \& TRAVIS G. BRADLEY \\ University of California, Davis
}

\begin{abstract}
Blevins \& Garrett $(1998,2004)$ argue that rhotic metathesis occurs when listeners reinterpret an elongated [low F3] feature in a non-historical position. However, not all cases are amenable to this account, as no single phonetic property unifies the class of rhotics. We examine two cases involving intrasyllabic rhotic metathesis: rightward movement of $/ \mathrm{B} /$ in French and leftward movement of $/ \mathrm{r} /$ in Spanish. In Optimality Theory (Prince \& Smolensky 1993), we formalize diachronic metathesis in terms of separate production and perception grammars, which account for the source of variance and the selection of innovative underlying forms, respectively. In production, gestural alignment constraints favor complete overlap of adjacent rhotic and vowel gestures, whose linear ordering is thereby rendered indeterminate. The output of the production grammar serves as input to the perception grammar, which maps surface forms to underlying forms in accordance with attested patterns of the language.
\end{abstract}

\section{Introduction}

Metathesis, or the linear reordering of phonological segments, is noted throughout Romance and other languages and frequently involves rhotics or " $\mathrm{r}$ like” phonemes. In a cross-linguistic survey, Blevins \& Garrett (2004; see also 1998) identify four main types of metathesis. Perceptual metathesis results from the elongation of phonetic cues associated with a segment, which is subsequently reanalyzed in an innovative position. Compensatory metathesis involves stressinduced temporal shifts in VCV sequences. Coarticulatory metathesis affects adjacent stops that differ in place of articulation. Auditory metathesis results from the decoupling of sibilant noise from the speech stream. Instances of rhotic metathesis are subsumed under the category of perceptual metathesis. Crucial to their analysis is the feature rhoticity, which they define in terms of low or lowered third formant (F3) resonance (2004:123). Rhotic metathesis is triggered by the elongation of low F3 across a rhotic-vowel or vowel-rhotic domain, whereby listeners reinterpret the spread-out feature in a non-historical position.

\footnotetext{
* For helpful comments and discussion, we would like to thank Laura Colantoni, Carlos-Eduardo Piñeros, and Jeffrey Steele, and audience members at the $37^{\text {th }}$ Linguistic Symposium on Romance Languages, held March 15-18, 2007, by the University of Pittsburgh. This paper has also benefited from the comments of three anonymous reviewers. We are responsible for any shortcomings.
} 
A review of the phonetic characteristics of rhotics poses several problems for a perceptual account based on the feature rhoticity. Foremost among these is the absence of a single phonetic property which plausibly defines the phonological class of rhotics (for discussion of rhoticity and possible rhotic classhood, see Lindau 1985, Ladefoged \& Maddieson 1996:244-5, Wiese 2001, Russell Webb 2002). Most importantly, not all rhotics involve gestures resulting in a low or lowered F3. For example, the apical flap or tap [r] involves an extra-short duration of constriction and minimal formant structure. Both the velar/uvular fricative [ $\mathrm{B}$ ] and the uvular trill [R] involve a relatively high $\mathrm{F} 3(3000 \mathrm{~Hz}$ or greater). Indeed, only coronal approximant rhotics, such as the bunched $[\mathrm{I}]$ of American English, can be plausibly subsumed under Blevins \& Garrett's definition of rhoticity. It may be preferable to define the class of rhotics in more abstract terms, based on cross-linguistic similarities in phonotactic distributions and phonological alternations (see, e.g., Russell Webb 2002, Walsh Dickey 1997, Wiese 2001), but such a definition is incompatible with Blevins \& Garrett's explanation, as the latter depends upon an acoustic property with long duration, and not a paradigmatic or syntagmatic relation. In sum, few cases of rhotic metathesis are amenable to a perceptual account involving low F3.

In this paper, we examine two cases of intrasyllabic rhotic metathesis in Romance: rightward movement of $/ \mathrm{s} /$ in French and leftward movement of $/ \mathrm{r} /$ in Spanish (\$2). We argue that an adequate analysis should take into account both productive (i.e., articulatory) and receptive (i.e., perceptual) knowledge and demonstrate the interaction of these in sequenced grammars (§3). From this analysis, it emerges that knowledge relevant to consonant-vowel overlap and vowel intrusion underlies productive innovation (§4), and that perceptual habituation and parsing of innovative auditory input lead to the eventual selection of novel phonological forms (§5). Proposed diachronic scenarios accounting for rhotic metathesis involve both articulation and perception, underscoring the conspiracy between different phonological knowledge types in sound change.

\section{Data}

A comparison of data from non-standard French and Spanish dialects reveals an asymmetry in the directionality of historical rhotic-vowel metathesis within the syllable. ${ }^{1}$ In non-standard French varieties, many words now have unstressed $/ \mathrm{CV}$ / where their Standard correspondents have /СьV/, as seen in (1). Leftward metathesis, /CVв/ > /Сь V/, is attested but atypical.

\begin{tabular}{|c|c|c|}
\hline & $\underline{\text { Standard form }}$ & Dialectal form \\
\hline ret & рвœmje & pвъmje \\
\hline & bsœtõ & besto \\
\hline
\end{tabular}

\footnotetext{
${ }^{1}$ Our data sources include the following: for Normand French, Desgrippes (1982:55), Grammont (1965:239-248, 1905 [=1950]); for varieties spoken in Saint Pol sur Ternoise/Pas de Calais and St. Pierre-Port/Guernsey, Atlas Linguistique de France [Giliéron \& Edmont 1968] n. 284, 399; for popular Spanish dialects, Lipski (1990), which is based on "[his] own fieldwork in many Spanishspeaking regions as well as a cross section of published descriptions" (90, Fn. 2) cited therein. The examples presented here are representative of the most frequently attested patterns.
} 


\begin{tabular}{|c|c|c|c|}
\hline frémir & fветів & $\mathrm{f} \varepsilon$ bmi & 'shake' \\
\hline entreprise & ãtвœрвіz & ёtєврве & 'business' \\
\hline vendredi & vãdвœdi & vãdœвdi & 'Friday' \\
\hline $\begin{array}{l}\text { crever } \\
\text { grelot }\end{array}$ & $\begin{array}{l}\text { kьœve } \\
\text { gвœlo }\end{array}$ & $\begin{array}{l}\text { kœьve } \\
\text { gœьlo }\end{array}$ & $\begin{array}{l}\text { 'die, waste away' } \\
\text { 'bell' }\end{array}$ \\
\hline
\end{tabular}

Rightward metathesis is also attested in word-initial position, as shown by the examples in (2).

(2)

\begin{tabular}{|c|c|c|c|}
\hline & $\underline{\text { Standard form }}$ & Dialectal form & \\
\hline refroidir & $\overline{\text { sœf } \text { swadis }}$ & aвfьwadis & 'cool down' \\
\hline regorger & вœgовзе & авяовзе & ‘spill out' \\
\hline relier & вœlje & abloje & 'bind' \\
\hline remanier & вœmanje & asmane & 'revise' \\
\hline renifler & вœnifle & asnifle & 'sniff' \\
\hline repas & вœра & авpas & ‘meal’' \\
\hline relevée & вœløve & ableve $e^{j}$ & 'spicy, refined' \\
\hline
\end{tabular}

In popular Spanish, many inherited words that contained unstressed /CVs/ demisyllables now have corresponding $/ \mathrm{CrV} /$, as seen in (3), but rightward metathesis, $/ \mathrm{CrV} />/ \mathrm{CV} r /$, is infrequent and considered exceptional (Lipski 1990:92). ${ }^{2}$

\begin{tabular}{|c|c|c|}
\hline Standard form & Dialectal form & \\
\hline$\overline{\text { abarcar }}$ & $\overline{\text { abracar }}$ & 'to cover, take on' \\
\hline conturbiar & controbiar & 'to disturb, bother' \\
\hline deperder & depreder & 'to lose' \\
\hline deperdición & depredición & 'loss’' \\
\hline intervalo & intrevalo & 'interval' \\
\hline pedernal & pedrenal & 'flint' \\
\hline dormir & drumir & 'to sleep' \\
\hline fortuna & frutuna & 'fortune' \\
\hline garbanzo & grabanzo & 'chickpea' \\
\hline perdonar & predonar & 'to pardon' \\
\hline perfecto & prefecto & 'perfect' \\
\hline permiso & premiso & 'permission' \\
\hline perspicaz & prespicaz & 'perceptive, sharp' \\
\hline porfiar & profiar & 'to insist' \\
\hline
\end{tabular}

In sum, rhotic metathesis operates in a rightward direction in the French data, transposing /s/ with a following vowel in both C_C and \#_C contexts. The

\footnotetext{
${ }^{2}$ Lipski (1990) provides two examples of leftward metathesis within a stressed syllable: taberna > tabrena 'tavern' and turbio > trubio 'cloudy, muddy'. Other examples show / $/$ / moving leftward into a preceding syllable: fábrica > frábica 'factory', madre > marde 'mother'. See Bradley (2007a) for an Optimality-theoretic analysis of metathesis involving several types of sonorant consonants in Judeo-Spanish, including long-distance movement of / $/$.
} 
Spanish data show the opposite directionality, whereby / $/$ / is transposed with a preceding vowel in C_C contexts.

\section{Theoretical orientation}

Contemporary work on sound change has placed relatively greater emphasis on the role of listeners in diachronic innovation (e.g., Blevins 2004, Ohala 1993), presumably in response to the prior emphasis placed on factors such as ease of articulation and productive economy (e.g., Martinet 1964). As such, the speaker is considered to be responsible for variant surface forms and the listener for the selection of one or more of these and their innovative categorization; when the underlying form of the listener differs from that of the speaker, change has occurred (see e.g., Haspelmath 1999, McMahon 2000). Insights gleaned from these theories notwithstanding, several considerations remain unaddressed with regard to rhotic metathesis as a listener-instantiated process. Most notably, it is observed (see §4) that gestural innovation is not always haphazard but is in many instances governed by phonological knowledge. The approach advocated here assumes that any account of sound change, in general, and of rhotic metathesis, in particular, must refer to all phonological knowledge. Where there is strong evidence for knowledge involved in speech production, the analysis must consider the complementary roles of speakers and listeners in order to achieve a tenable description and explanation of diachronic data.

\section{Articulation: formalizing productive knowledge}

In this section, we examine phonetic patterns of Spanish and French rhotics in consonant clusters, developing a formal account of the gestural configurations that ultimately give rise to intrasyllabic metathesis.

\subsection{Vowel intrusion in Spanish and rhotic lenition in French}

Transitory vowels are well documented in Spanish consonant clusters that contain /r/. For a review, see Blecua (2001) and more recently, Bradley (2005, 2007c) and Colantoni \& Steele (2005, 2007). Following Hall (2003, 2006), we refer to the transitory vowels as intrusive vowels and to the phenomenon itself as vowel intrusion. ${ }^{3}$ In an acoustic study of Peninsular Spanish rhotics, Blecua (2001) finds that vowel intrusion occurs at a higher frequency in tautosyllabic /Cr/ onsets than in heterosyllabic /rC/ clusters (78.8\% vs. 63\%). Sample realizations of such clusters are illustrated by the waveforms in Figure 1. In (a), an intrusive vowel intervenes between the constriction period of the voiceless dental stop and the following apical tap. In (b), the tap constriction is adjacent to that of the following nasal, without an intrusive vowel. Other phonetic realizations are attested in these contexts, e.g., sporadic deletion of $/ \mathrm{r} /$ in complex onsets and emphatic trilling of $/ \mathrm{r} /$ in coda. Nonetheless, intrusive vowels appear more frequently in $/ \mathrm{Cr} /$ than $/ \mathrm{rC} /$.

\footnotetext{
${ }^{3}$ This terminological distinction is necessary to distinguish vowel intrusion from phonological vowel epenthesis. See Hall (2003, 2006) for a discussion of vowel intrusion diagnostics.
} 


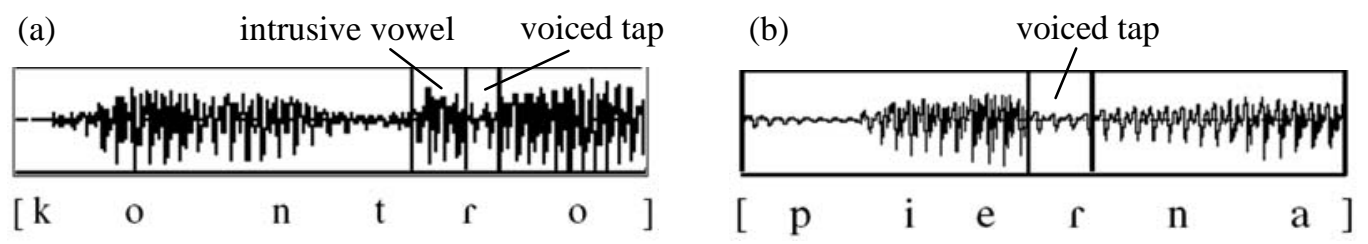

Figure 1: (en)contró ‘s/he found’ vs. pierna ‘leg’ (Blecua 2001:\$3.1.1, §3.2.1)

Bradley (1999, 2004, 2005, 2007b,c) and Hall (2003, 2006), building upon a proposal by Steriade (1990), analyze vowel intrusion within the Articulatory Phonology framework (Browman \& Goldstein 1989 et seq.). In these analyses, intrusive vowels are the result of a vowel gesture being heard between two adjacent consonant gestures that are minimally overlapped. While vowel intrusion is a variable phenomenon in Peninsular Spanish, there is a clear tendency for intrusive vowels to appear more often in /Cr/ onsets than in /rC/ sequences, which suggests that onset clusters are less susceptible to gestural overlap than are heterosyllabic clusters.

In French, there is an allophonic distribution of fricative and approximant rhotics (Russell Webb 2002, in press-a,b, Tranel 1987, Walker 2001). Fricative $[\mathrm{b}]$ appears after obstruents and in word-initial position, as in (4a), while approximant $[\underset{\mathrm{r}}{\mathrm{r}}]$ appears between vowels and in coda position, as in (4b). ${ }^{4}$

\begin{tabular}{|c|c|c|c|}
\hline (4) $\mathrm{a}$. & brosse & [bвоs] & 'brush'5 \\
\hline & pro & [рво] & ‘pro’' \\
\hline & robe & [воb] & ‘dress’ \\
\hline b. & morose & [mob̦ & 'morose' \\
\hline & orgue & 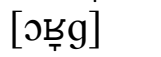 & ‘organ’ \\
\hline & or & {$[\mathrm{o} \underset{\mathrm{T}}{\mathrm{T}}]$} & 'gold' \\
\hline
\end{tabular}

Widely acknowledged descriptions in the literature make it clear that $/ \mathrm{B} /$ is more likely to undergo weakening or approximantization in $/ \mathrm{VbC} /$ sequences than in $/ С в \mathrm{~V} /$. In all subsequent discussion, we use the IPA lowering diacritic in a narrow transcription of $[\underset{\mathrm{r} C}{\mathrm{H} C}]$ clusters, following the examples in (4b).

As we will show in $\S 5$, the relatively higher frequency of vowel intrusion in Spanish /Cr/ and of rhotic lenition in French / $\mathrm{sC} /$ has consequences for the perception grammar of each language and is key to explaining the directionality asymmetry observed in intrasyllabic metathesis.

\subsection{The articulatory origins of intrasyllabic rhotic metathesis}

As in the case of vowel intrusion with Peninsular Spanish / $/$, Articulatory Phonology can also model certain types of $\mathrm{C} / \mathrm{V}$ metathesis as the movement of a consonant gesture across a tautosyllabic vowel gesture (Steriade 1990). Based on

\footnotetext{
${ }^{4}$ We abstract away from voicing assimilation, which targets both post- and preconsonantal $/ \mathrm{b} /$.

${ }^{5}$ For Quebec and European French, Colantoni \& Steele (2005, 2007) document vowel intrusion in /Сь/ complex onsets, but only when the initial C is [+voice] (е.g., brosse [ $\mathrm{b}^{\text {}}$ ьоs], cf. (4a)). They do not consider /sC/ clusters.
} 
a typological survey of vowel intrusion in consonant clusters, Hall (2003) establishes the hierarchy in (5), which also has implications for the analysis of intrasyllabic metathesis.

(5) obstruents $\rightarrow$ glides, nasals $\rightarrow[\mathrm{r}] \rightarrow[1] \rightarrow[\mathrm{c}],[\mathrm{b}] \rightarrow$ gutturals

If a given consonant type can be completely overlapped by a tautosyllabic vowel, then so can other types to the right in the hierarchy. Interestingly, the greater propensity of $[\mathrm{r}]$ and $[\mathrm{B}]$ to tolerate complete overlap by an adjacent vowel correlates with the frequent metathesis of these rhotics within the syllable, as seen in the data from non-standard French and Spanish.

Following recent work in gestural Optimality Theory (Bradley 2005, 2007b,c, Davidson 2003, Gafos 2002, Hall 2003), we formalize a production grammar accounting for variation in the coordination of rhotics and vowels within the syllable. In this framework, alignment constraints coordinate articulatory gestures with reference to temporal landmarks, as shown in (6) (Gafos 2002). ${ }^{6}$

(6) a. ALIGN $\left(\mathrm{G}_{1}\right.$, LANDMARK $_{1}, \mathrm{G}_{2}$, LANDMARK $\left._{2}\right)$

Align landmark of gesture $_{1}$ with landmark of gesture $_{2}$.

b.

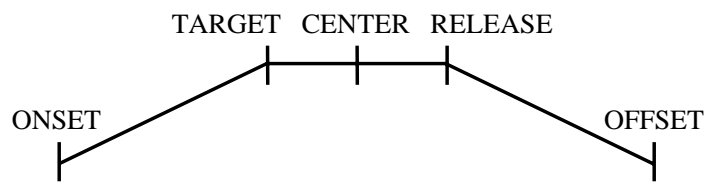

More specifically, we propose the context-specific constraint in (7), abbreviated as $\mathrm{C} / \mathrm{N}$-OVERLAP, which requires the consonant gesture of an interconsonantal $\mathrm{CV}$ or VC sequence to be centered on the adjacent vowel gesture. ${ }^{7}$

ALign(C, CENTER // V, CENTER) In C_C (=C//V-OverLAP)

In an interconsonantal $/ \mathrm{CV} /$ or $/ \mathrm{VC} /$ sequence, align the center of $\mathrm{C}$ with the center of $\mathrm{V}$.

Hall (2003) formalizes the implicational hierarchy of vowel intrusion triggers in (5) as a universal ranking of markedness constraints, shown in (8).

(8) a. *GESTURE IN GESTURE $_{\mathrm{Y}}$

A gesture of type $y$ does not fully surround a gesture of type $x$.

\footnotetext{
${ }^{6}$ Not all phonologists agree on the proper location of gestural representations and constraints within the grammar. See Hall (2003) and more recently, Bradley (2005, 2007b,c), for an explanation of why it is unnecessary to relegate gestural coordination to a low-level phonetic implementation component, as long as the phonological grammar contains no faithfulness constraints on input coordination. See also Boersma (2007a,b), who proposes a more elaborate model of speech production involving multiple representational levels and constraint types.

${ }^{7} \mathrm{C} / / \mathrm{V}$-OVverLAP should probably be expanded to include both \#_C and C_C contexts, in order to account for word-initial /sV/ metathesis in French (2). Alternatively, word-initial shifts may have begun in postconsonantal phrasal contexts and then become lexicalized.
} 


\section{b. *ObStRuent in $\mathrm{V}$ » *GLide IN $\mathrm{V}$, *NASAL in $\mathrm{V}$ » *[r] IN $\mathrm{V}$ » *[l] IN $\mathrm{V}$ » *[r] IN V, *[r] IN V » *GUTtURAL IN V}

Ranking C//V-OverLAP along the hierarchy in (8b) distinguishes those consonants that can move across an adjacent vowel from those consonants that cannot. We propose a variable ranking of the overlap constraint with * $[r]$ IN $\mathrm{V}$ and *[ $\mathrm{b}]$ IN V. When C//V-OverLap falls above these constraints in a particular evaluation, both rhotic gestures must be centered at the mid-point of a tautosyllabic vowel. Figure 2 illustrates the effects of this ranking for the segmental strings /CRVC/ and /CVRC/ (where ' $\mathrm{R}$ ' is a cover symbol encompassing both types of rhotic). Maximal overlap of the rhotic-vowel sequence produces an auditory form in which the vowel gesture is heard as two symmetrically intrusive vowels on either side of the rhotic, as shown in (a) for Spanish and in (b) for French. Furthermore, blending of the tongue body gesture of uvular $/ \mathrm{b} /$ with the tongue body gesture of the vowel reduces the rhotic constriction to that of an approximant [⿶凵్] in (b). Overlap of $/ \mathrm{f} /$ and the tongue body gesture of a vowel does not produce gestural blending since apical / $/ \mathrm{f}$ engages a different articulator.

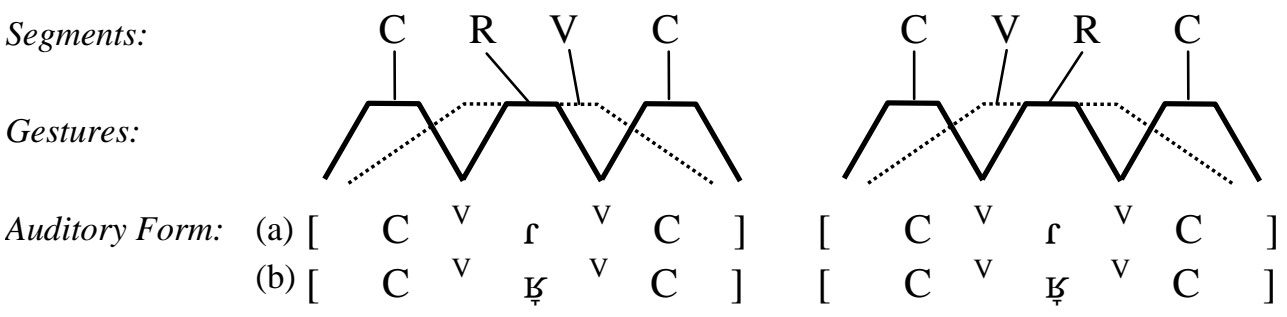

Figure 2: Centering of the rhotic gesture on a tautosyllabic vowel

Alternatively, maximal overlap of $/ \mathrm{s} /$ and the tautosyllabic vowel in French may best be considered an instance of vowel elision and syllabic $/ \mathrm{b} /$. In the majority of cases, intrasyllabic rhotic metathesis occurred when the adjacent vowel was schwa. This vowel is unique in French in that it is the only vowel subject to elision in certain environments. On the common assumption that syllabic consonants are longer than their non-syllabic counterparts, a lengthened tongue body gesture for $/ \mathrm{b} /$ in Figure 2 would eclipse the tongue body gesture for schwa, and the symmetrically intrusive vowels would be absent from the auditory form, i.e., [Сங̦:C]. Alternatively, schwa elision might involve deletion of a phonological segment and its associated tongue body gesture. Space limitations prevent us from developing a comprehensive formal account here.

The interaction of gestural coordination constraints is shown in Tableau 1 for $/ \mathrm{CrVC} /$ and $/ \mathrm{CVrC} /$ strings in Spanish. Candidates (a) and (c) violate $\mathrm{C} / / \mathrm{V}$ OVERLAP because the gestures of the interconsonantal $/ \mathrm{rV} /$ and $/ \mathrm{Vr} /$ sequences are not centered on one another. Since C//V-OverLAP dominates * $[\mathrm{r}]$ IN V, maximal overlap between the tap and the vowel is optimal in candidates (b) and (d). 


\begin{tabular}{|c|c|c|}
\hline$/ \mathrm{CrVC/}$ & C//V-OVERLAP & $*[r] \mathrm{IN} \mathrm{V}$ \\
\hline a. $X X /{ }_{\left[{ }^{[} C^{v} r V C\right]_{\mathrm{AudF}}}$ & $* !$ & \\
\hline$\because$ b. $\sqrt{\left[\mathrm{C}^{\mathrm{V}} \mathrm{r}^{\mathrm{V}} \mathrm{C}\right]_{\mathrm{AudF}}}$ & & * \\
\hline$/ \mathrm{CV} r \mathrm{C} /$ & & \\
\hline c. $\sqrt{ }{ }_{[\mathrm{CV} r C]_{\mathrm{AudF}}}$ & $* !$ & \\
\hline$\because$ d. $\sqrt{2}{ }_{\left[\mathrm{C}^{\mathrm{V}} \mathrm{r}^{\mathrm{V}} \mathrm{C}\right]_{\text {AudF }}}$ & & * \\
\hline
\end{tabular}

Tableau 1: Maximal overlap of /rV/ and /Vr/ sequences in Spanish

As shown in Tableau 2, the analysis works the same for French. Candidates (a) and (c) violate $\mathrm{C} / / \mathrm{V}$-OVERLAP because the $/ \mathrm{s} \mathrm{V} /$ and $/ \mathrm{V} \mathrm{b} /$ sequences are not

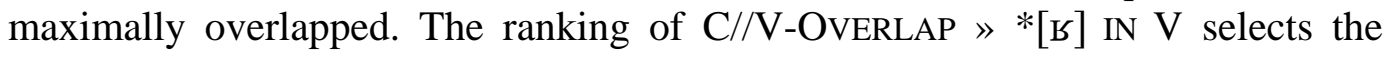
gestural coordinations in candidates (b) and (d), in which maximal overlap

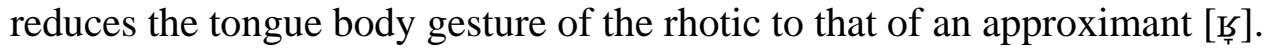

\begin{tabular}{|c|c|c|c|}
\hline \multicolumn{2}{|l|}{ /СьVC/ } & C//V-OVERLAP & $*[\mathrm{~b}] \mathrm{IN} \mathrm{V}$ \\
\hline 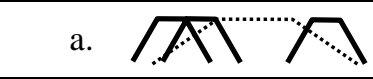 & {$[\mathrm{CuVC}]_{\mathrm{AudF}}$} & $* !$ & \\
\hline$\rightarrow$ b. $\sqrt{ }$ & {$\left[\mathrm{C}^{\mathrm{V}_{\mathrm{K}}{ }^{\mathrm{V}} \mathrm{C}}\right]_{\mathrm{AudF}}$} & & * \\
\hline /CVвC/ & & & \\
\hline с. $\sqrt{A}$ & {$\left[\mathrm{CV} \mathrm{VWC}_{\mathrm{AudF}}\right.$} & $* !$ & \\
\hline$\rightarrow$ d. $\sqrt{ } \sqrt{ }$ & {$\left[C^{\mathrm{V}}{ }_{W}^{\mathrm{V}} \mathrm{C}\right]_{\text {AudF }}$} & & * \\
\hline
\end{tabular}

Tableau 2: Maximal overlap of /sV/ and / $\mathrm{Vb} /$ sequences in French

Higher-ranking constraints of the hierarchy in (8b) keep other consonant types from being maximally overlapped by a tautosyllabic vowel. For example, the high ranking of *[l] IN V in both French and Spanish prevents maximal overlap of interconsonantal /lV/ and /Vl/ sequences, as seen in (a) and (c) of Tableau 3.

\begin{tabular}{|c|c|c|}
\hline /ClVC/ & $*^{*[1]} \mathrm{IN} \mathrm{V}$ & 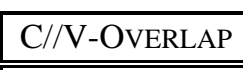 \\
\hline 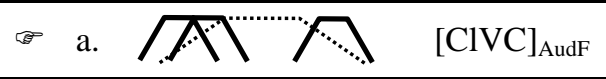 & & * \\
\hline b. $\sqrt{2}{ }_{\left[\mathrm{C}^{\mathrm{V}} \mathrm{l}^{\mathrm{V}} \mathrm{C}\right]_{\mathrm{AudF}}}$ & $* !$ & \\
\hline /CVlC/ & & \\
\hline 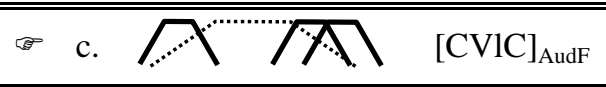 & & * \\
\hline d. $\sqrt{2}{ }_{\left[{ }^{\mathrm{V}} \mathrm{l}^{\mathrm{V}} \mathrm{C}\right]_{\mathrm{AudF}}}$ & *! & \\
\hline
\end{tabular}

Tableau 3: Minimal overlap of /lV/ and /Vl/ sequences in Spanish and French 
As demonstrated above, the production grammars of Spanish and French yield occasional outputs in which / / / and /s/ (but not other consonants) are maximally overlapped by a tautosyllabic vowel. As shown in Figure 2, maximal overlap has the effect of neutralizing the underlying linear order of /CRVC/ and /CVRC/ strings. Based on the auditory forms alone, it is not obvious whether $\left[\mathrm{C}^{\mathrm{V}} \mathrm{f}^{\mathrm{V}} \mathrm{C}\right]_{\text {AudF }}$ corresponds to input $/ \mathrm{CrVC} /$ or $/ \mathrm{CVrC} /$ in Spanish, nor whether $\left[\mathrm{C}^{\mathrm{V}}{ }_{\mathrm{S}}{ }^{\mathrm{V}} \mathrm{C}\right]_{\mathrm{AudF}}$ corresponds to input /СьVC/ or /CVвC/ in French.

\section{Perception: formalizing receptive knowledge}

Recent work in Optimality Theory has focused on the interaction of constraints in the perception grammar (Boersma 1998, 2007a,b, Russell Webb in press-a). In the present study, we assume that the output of the production grammar pairs a gestural representation with its corresponding auditory form, as seen in the tableaux of the previous section. The auditory form then serves as input to a separate perception grammar, which formalizes the listener's mapping of continuous cues in the auditory form to discrete phonological elements in the underlying form. We assume that the perception grammar consists of faithfulness constraints, as in (9a), which regulate correspondence between input auditory forms and output underlying forms, and markedness constraints, as in (9b), which promote structural well-formedness in output underlying forms. ${ }^{8}$

(9) a. $\operatorname{PARSE}(x)$

Surface item $x$ appears in the underlying form.

b. ${ }^{*} \operatorname{CATEG}(x, v)$

Surface item $x$ is not recognized as the value $v$ (i.e., the value $v$ is not a categorization of $x$ ).

The ranking of PARSE and *CATEG establishes a formal model of perceptual habituation, reflecting the listener's knowledge of learned phonotactic patterns, and attenuation to gradient detail (Hume 2004, Kuhl \& Iverson 1995, Kuhl et al. 1992, Peperkamp \& Dupoux 2003). In this instance, habituation refers to listeners' relative attention to novel detail in the auditory input; listeners are more habituated to typical patterns of the language and less habituated to novel patterns. Habituation to language patterns and attenuation to novel input can be formalized as the outcome of constraint interaction. For a given input to the perception grammar, the ranking of $\operatorname{PARSE}(x) »{ }^{*} \operatorname{CATEG}(x, v)$ predicts that $x$ will appear in the output underlying form, i.e., that $x$ will be posited as contrastive. The reverse ranking establishes that $x$ will fail to appear in the output underlying form, i.e., that $x$ will not be posited as contrastive.

\footnotetext{
${ }^{8}$ In the model of the perception grammar developed by Boersma (2007a,b, inter alia), (i) auditory forms are mapped to phonological surface forms through the interaction of cue constraints with structural markedness constraints; (ii) surface forms are mapped to underlying forms by interacting faithfulness and structural markedness constraints; and (iii) both of these mappings are carried out completely in parallel. The approach we pursue here simplifies the perception grammar somewhat, with a single mapping from auditory to underlying forms. See Boersma (2007a) for a more thorough discussion of multiple levels and constraint types in production and perception.
} 
Our formalization of perception grammars for French and Spanish is based on the constraints given in (10). (10a) requires that a vocoid in the auditory form be mapped to a corresponding vocoid in the underlying form, where 'vocoid' denotes both shorter intrusive and longer full vowels. (10b) prevents consonants from functioning as syllable peaks in the underlying form. The constraints in (10c,d) are ranked high in Spanish and French, respectively, and reflect the prototypical realizations of rhotics described in §4.1. Recall that for Peninsular Spanish, vowel intrusion is more frequent in tautosyllabic /Cr/ than in heterosyllabic /rC/. (10c) encodes the listener's knowledge that a vocalic element appearing before $[r]$ in the former cluster is most likely an intrusive vowel and not a phonologically-

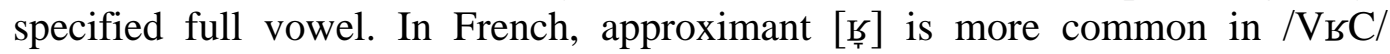
sequences than in $/ \mathrm{C} \mathrm{VV} /$. (10d) encodes the listener's knowledge that an approximant rhotic is most likely not prevocalic.

(10) a. PARSE(vocoid)

A vocoid in the auditory form appears in the underlying form.

b. *CATEg(C, peak)

A consonant is not recognized as a syllable peak.

c. ${ }^{*} \operatorname{CATEG}\left({ }^{\mathrm{V}} \mathrm{r}, \mathrm{V} r\right)$

A sequence $\left[{ }^{\mathrm{V}} \mathrm{r}\right]$ is not recognized as the sequence $/ \mathrm{V} r /$.

d. * $\operatorname{CATEG}(\underset{\mathrm{K}}{\mathrm{V}}, \mathrm{bV})$

A sequence $\left[{ }_{\leftarrow}^{\mathrm{V}}\right.$ ] is not recognized as the sequence $/ \mathrm{b} \mathrm{V} /$.

An anonymous reviewer worries that the type of *CATEG constraints formalized in (10c,d) can be a rather power mechanism and could include all kinds of segments and contexts. However, we are not the first to make use of such constraints in the perception grammar (see, e.g., Boersma 2007b, who employs cue constraints on segment sequences in an analysis of $h$-aspiré in French). Furthermore, (10c,d) are not specific to Spanish and French but instead are potentially high-ranking in any language with similar asymmetries involving vowel intrusion and rhotic approximantization. "The language-specificity of perception [...] corresponds to the freedom that every language possesses to rank the constraints in its own order" (Boersma 2007a:12).

The perception grammar for Spanish is illustrated in Tableau 4. The input is the auditory form [ $\mathrm{p}^{\mathrm{e}} \mathrm{c}^{\mathrm{e}}$ sona], which the speaker's grammar already selected as the optimal realization of underlying /persona/ 'person' (see candidate (d) of Tableau 1). Candidate (b) violates *CATEG(C, peak) because the input rhotic is mapped onto a syllable peak. Candidates (a) and (c) both violate ${ }^{*} \operatorname{CATEG}\left({ }^{\mathrm{V}} \mathrm{r}, \mathrm{V} r\right)$ because the intrusive vowel of input $\left[{ }^{\mathrm{e}} \mathrm{r}\right]$ is mapped onto the full vowel /e/. Candidate (d) violates PARSE(vocoid) because the same intrusive vowel has no output correspondent. Because PARSE(vocoid) ranks below ${ }^{*} \operatorname{CATEG}\left({ }^{\mathrm{V}} \mathrm{r}, \mathrm{Vr}\right)$, the violation is tolerated, and (d) emerges as optimal. In sum, Tableau 4 formalizes the listener's knowledge of Spanish phonotactic and phonetic patterns. Diachronic metathesis results from the listener's biased resolution of the indeterminate linear order of the auditory form [ $\mathrm{p}^{\mathrm{e}} \mathrm{c}^{\mathrm{e}}$ sona] in favor of the underlying form /presona/. 


\begin{tabular}{|c|c|c|c|}
\hline$\left[p^{e} r^{e} \text { sona }\right]_{\text {AudF }}$ & *CATEG(C, peak) & : *ATEG $\left({ }^{\mathrm{V}} \mathrm{r}, \mathrm{V} r\right)$ & PARSE(vocoid) \\
\hline a. /peresona/UF & & $* !$ & \\
\hline b. $/$ prsona/UF & $* !$ & 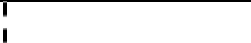 & $* *$ \\
\hline c. $/$ persona $/ \mathrm{UF}$ & 1 & $* !$ & * \\
\hline d. /presona/UF & 7 & $\begin{array}{l}T \\
\end{array}$ & * \\
\hline
\end{tabular}

Tableau 4: Metathesis: indeterminate [p $\mathrm{p}^{\mathrm{e}} \mathrm{e}$ sona] (</persona/ 'person') is mapped to historically innovative /presona/

Tableau 5 shows the evaluation of indeterminate [p ${ }^{\mathrm{e}} \mathrm{e}^{\mathrm{e}} \mathrm{sjo}$, which is the speaker's pronunciation of /presjo/ 'price' (see candidate (b) of Tableau 1). The constraints evaluate output underlying forms in the same way as in Tableau 4, with candidate (d) selected as optimal. Since the listener selects /presjo/, an underlying form that is identical to that of the speaker, intrasyllabic metathesis does not occur. By contrast, metathesis does occur in Tableau 4, since the optimal underlying form, /presona/, differs from that of the speaker, /persona/.

\begin{tabular}{|c|c|c|c|}
\hline$\left[\mathrm{p}^{\mathrm{e}} \mathrm{s}^{\mathrm{e}} \mathrm{sjo}\right]_{\mathrm{AudF}}$ & *CATEG(C, peak) & *CATEG $\left({ }^{\mathrm{V}} \mathrm{r}, \mathrm{Vr}\right)$ & PARSE(vocoid) \\
\hline a. $/$ peresjo/UF & i & $* !$ & \\
\hline b. $/ \mathrm{prsjo} / \mathrm{UF}$ & $* !$ & & ** \\
\hline c. $/$ persjo/UF & ; & $* !$ & * \\
\hline$\leftrightarrow \mathrm{d} . \quad / \mathrm{presjo} / \mathrm{UF}$ & i & i & * \\
\hline
\end{tabular}

Tableau 5: No metathesis: indeterminate [p $\mathrm{p}^{\mathrm{e}} \mathrm{e}$ sjo] (</presjo/ 'price') is mapped to etymological /presjo/

In some cases, intrusive vowels in Spanish /Cr/ clusters have been reinterpreted as full lexical vowels over time, e.g., crónica > corónica 'chronicle', trabilla > tarabilla 'stirrup', chacra > chácara 'farm' (see Bradley 2007c and the references cited therein). In the present analysis, such cases are easily accounted for by the occasional demotion of ${ }^{*} \operatorname{CATEG}\left({ }^{\mathrm{V}} r, \mathrm{~V} r\right)$ below PARSE(vocoid) in the perception grammar. As illustrated in Tableau 6, the listener maps the intrusive vowel of input [ $\left.\mathrm{k}^{\mathrm{o}} \mathrm{c}\right]$ onto the full vowel /o/ in candidate (b).

\begin{tabular}{|c|c|c|c|}
\hline & {$\left[\mathrm{k}^{\mathrm{o}} \text { ronika }\right]_{\text {AudF }}$} & PARSE(vocoid) & ${ }^{*}$ CATEG $\left({ }^{\mathrm{V}} \mathrm{r}, \mathrm{V} r\right)$ \\
\hline a. & /kronika/UF & $* !$ & \\
\hline$\leftrightarrow \mathrm{b}$ & /koronika/UF & & $*$ \\
\hline
\end{tabular}

Tableau 6: Epenthesis: the auditory form [ $\mathrm{k}^{\mathrm{o}}$ ronika] (</kronika/ 'chronicle') is mapped to historically innovative /koronika/

Tableau 7 exemplifies the interaction of perceptual constraints in the evaluation of the French auditory input $\left[\mathrm{k}^{\partial} \mathrm{S}^{2} \mathrm{ve}\right]$, which is the speaker's pronunciation of /krəve/ 'die' (see candidate (b) of Tableau 2). Evaluation 
proceeds in a manner similar to the Spanish perception grammar, except that *CATEG $(\underset{\mathrm{L}}{\mathrm{V}}, \mathrm{bV})$ replaces ${ }^{*} \mathrm{CATEG}\left({ }^{\mathrm{V}} \mathrm{r}, \mathrm{Vr}\right)$. The grammar selects $/ \mathrm{kəbve/} \mathrm{in} \mathrm{(c)} \mathrm{as}$ the optimal output, leading to a diachronically distinct underlying form.

\begin{tabular}{|c|c|c|c|c|}
\hline & {$\left[\mathrm{k}^{2} \mathrm{ST}^{2} \mathrm{ve}\right]_{\mathrm{AudF}}$} & *CATEG(C, peak) & 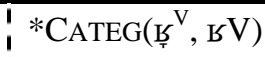 & PARSE(vocoid) \\
\hline & а. /kәьәvе/UF & & $* !$ & \\
\hline & b. $/ \mathrm{kbve} / \mathrm{UF}$ & $* !$ & i & ** \\
\hline 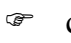 & с. /kәьve/UF & & 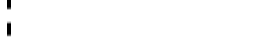 & * \\
\hline & d. /krəve/UF & & $* !$ & * \\
\hline
\end{tabular}

Tableau 7: Metathesis: indeterminate [ $\left.\mathrm{k}^{2} \mathrm{H}^{2} \mathrm{ve}\right]$ (</kьəve/ 'die') is mapped to historically innovative /kəьve/

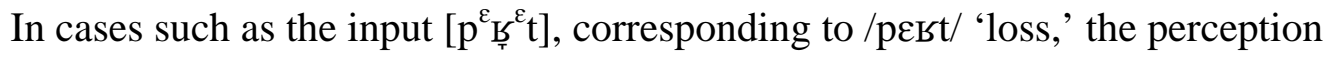
grammar selects an underlying form that is identical to that of the speaker, and intrasyllabic metathesis does not occur. This is exemplified in Tableau 8.

\begin{tabular}{|c|c|c|c|c|}
\hline & {$\left[\mathrm{p}^{\varepsilon} \mathrm{S}^{\varepsilon} \mathrm{t}\right]_{\mathrm{AudF}}$} & *CATEG(C, peak) ! & $\mathrm{G}\left(\mathrm{Ь}^{\mathrm{V}}, \mathrm{в} \mathrm{V}\right)$ & PARSE(vocoid) \\
\hline & а. $/ \mathrm{p} \varepsilon ь \varepsilon \mathrm{t} / \mathrm{UF}$ & I & $* !$ & \\
\hline & b. $/ \mathrm{put} / \mathrm{UF}$ & $* !$ & & $* *$ \\
\hline & c. $/ \mathrm{p} \varepsilon \mathrm{Bt} / \mathrm{UF}$ & $i$ & & * \\
\hline & 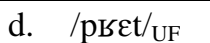 & $i$ & *! & * \\
\hline
\end{tabular}

Tableau 8: No metathesis: indeterminate $\left[\mathrm{p}^{\varepsilon} \mathrm{S}_{\mathrm{s}}^{\varepsilon} \mathrm{t}\right](</ \mathrm{p} \varepsilon \mathrm{bt} /$ 'loss') is mapped to etymological /peьt/

\section{Concluding remarks}

In the present work, we advocate an approach to perceptual metathesis in French and Spanish which considers both articulatory and perceptual factors. In many respects, this proposal represents an extension of Blevins \& Garrett (2004) and similar analyses. In discussing the implications of their perceptual account, Blevins \& Garrett acknowledge the possibility that some types of rhotic metathesis may involve the reinterpretation of transitory vowels:

[O]ur approach predicts the possible existence of some metathesis patterns that we have not yet encountered. Such predicted but unattested metatheses include $r V>V r$ (or the reverse). The articulation of taps typically involves transitory vowels preceding and following the brief constriction; if a phonetically predictable transition is reinterpreted as a full vowel, and a historical vowel is reinterpreted as a transition, metathesis will have occurred (Blevins \& Garrett 2004:141).

In a diachronic study of Slavic languages, Jetchev (1995) had already proposed an explanation of Bulgarian rhotic-vowel metathesis in terms of the reinterpretation of transitory vowels. Recall the alternative hypothesis for French involving schwa 
elision and syllabic / $\mathrm{b} /$ formation, as discussed in §4.2. In a cross-linguistic survey of syllabic consonants, Bell (1978:168) had already noted that one source of vowel-consonant metathesis is the loss of the consonant's syllabicity followed by vowel epenthesis.

Independently of any preconceived notion of rhoticity, our analysis is founded upon the complementary roles of productive and receptive knowledge, as well as the importance of language-specific patterns in the generation of variant auditory forms and in the parsing of diachronically innovative underlying forms. Building upon proposals of Blevins \& Garrett $(1998,2004)$ and related works, the present analysis specifically includes phonologically governed, predictable articulatory patterns, formalized in a constraint-based production grammar. The output of the production grammar serves as the basis for perceptually-induced shifts affecting the linear sequence, themselves the output of a separate perception grammar. Our approach has implications for the treatment of sound change and, especially, for any analysis of phonological behavior involving rhotics. While providing a definition of rhotic classhood is beyond the scope of the present work, an extension of the approach taken here to similar phonological patterns involving phonetically distinct rhotics might serve as a starting point for closer examination of cross-linguistic similarities among such segments, absent of ad hoc groupings or prima facie classhood.

\section{REFERENCES}

Bell, Alan. 1978. "Syllabic Consonants". Universals of Human Language ed. by Joseph Greenberg, vol. II, 153-201. Stanford: Stanford University Press.

Blecua, Beatriz. 2001. Las vibrantes en español: manifestaciones acústicas y procesos fonéticos. Ph.D. dissertation, Universitat Autònoma de Barcelona.

Blevins, Juliette. 2004. Evolutionary Phonology. Cambridge: Cambridge University Press.

--------- \& Andrew Garrett. 1998. “The Origins of Consonant-vowel Metathesis”. Language 74:2.508-556.

-------- \& Andrew Garrett. 2004. “The Evolution of Metathesis”. Phonetically Based Phonology ed. by Bruce Hayes, Robert Kirchner \& Donca Steriade, 117-156. Cambridge: Cambridge University Press.

Boersma, Paul. 1998. Functional Phonology: Formalizing the interactions between articulatory and perceptual drives. Leiden: Holland Academic.

--------. 2007a. "Cue Constraints and Their Interactions in Phonological Perception and Production”. Rutgers Optimality Archive [ROA \#944].

-------. 2007b. "Some Listener-oriented Accounts of $h$-aspiré in French". Lingua 117:12.1989-2054.

Bradley, Travis G. 1999. "Assibilation in Ecuadorian Spanish: A PhonologyPhonetics Account". Formal Perspectives on Romance Linguistics ed. by Jean-Marc Authier, Barbara E. Bullock \& Lisa A. Reed, 57-71. Amsterdam \& Philadelphia: John Benjamins. 
---------. 2004. "Gestural Timing and Rhotic Variation in Spanish Codas". Laboratory Approaches to Spanish Phonology ed. by Timothy L. Face, 197224. Berlin: Mouton de Gruyter.

--------. 2005. "Systemic Markedness and Phonetic Detail in Phonology". Experimental and Theoretical Approaches to Romance Linguistics ed. by Randall Gess \& Ed Rubin, 41-62. Amsterdam \& Philadelphia: John Benjamins.

-------. 2007a. "Constraints on the Metathesis of Sonorant Consonants in JudeoSpanish”. Probus 19:2.171-207.

--------. 2007b. "Morphological Derived-Environment Effects in Gestural Coordination: A Case Study of Norwegian Clusters”. Lingua 117:6.950-985.

--------. 2007c. "Spanish Complex Onsets and the Phonetics-Phonology Interface". Optimality-Theoretic Studies in Spanish Phonology ed. by Fernando Martínez-Gil \& Sonia Colina, 15-38. Amsterdam \& Philadelphia: John Benjamins.

Browman, Catherine \& Louis Goldstein. 1989. "Articulatory Gestures as Phonological Units". Haskins Laboratories Status Report on Speech Research, SR-99/100.69-101.

Colantoni, Laura \& Jeffrey Steele. 2005. "Phonetically-driven Epenthesis Asymmetries in French and Spanish Obstruent-liquid Clusters". Experimental and Theoretical Approaches to Romance Linguistics ed. by Randall Gess \& Ed Rubin, 77-96. Amsterdam \& Philadelphia: John Benjamins.

---------. 2007. "Voicing-dependent Cluster Simplification Asymmetries in Spanish and French". Segmental and Prosodic Issues in Romance Phonology ed. by Pilar Prieto, Joan Mascaró \& Maria-Josep Solé, 109-129. Amsterdam \& Philadelphia: John Benjamins.

Davidson, Lisa. 2003. The Atoms of Phonological Representation: Gestures, coordination, and perceptual features in consonant cluster phonotactics. Ph.D. dissertation, Johns Hopkins University.

Desgrippes, Bernard. 1982. "Le patois du domfrontais”. Le Pays Bas-Normand 165.1. Flers: Imp. E. Vicq.

Gafos, Adamantios. 2002. "A Grammar of Gestural Coordination”. Natural Language and Linguistic Theory 20.269-337.

Gilliéron, Jules \& Edouard Edmont. 1968. Atlas linguistique de la France. Bologna: Forni.

Grammont, Maurice. 1950. Traité de phonétique. Paris: Delagrave.

--------. 1965. Traité de phonétique avec 179 figures [La métathèse dans le parler de Bagnères-de-Luchon ]. Paris: Delagrave.

Hall, Nancy. 2003. Gestures and Segments: Vowel intrusion as overlap. PhD dissertation, University of Massachusetts, Amherst.

--------. 2006. “Cross-linguistic Patterns of Vowel Intrusion”. Phonology 23.387-429.

Haspelmath, Martin. 1999. “Optimality and Diachronic Adaptation”. Zeitschrift für Sprachwissenschaft 18:2.180-205.

Hume, Elizabeth. 2004. "The Indeterminacy/Attestation Model of Metathesis”. Language 80:2.203-237. 
Jetchev, Georgi. 1995. "Rhotics, Jers and Schwa in the History of Bulgarian". Paper presented at the 13th ICPhS, Stockholm, August 1995.

Kuhl, Patricia \& Paul Iverson. 1995. "Linguistic Experience and the 'Perceptual Magnet Effect"'. Speech Perception and Linguistic Processing: Issues in Cross-Linguistic Research ed. by Winifred Strange, 121-154. Baltimore: York Press.

Kuhl, Patricia, Karen Williams, Francisco Lacerda, Kenneth Stevens \& Björn Lindblom. 1992. "Linguistic Experience Alters Phonetic Perception in Infants by 6 Months of Age”. Science 255.606-608.

Ladefoged, Peter \& Ian Maddieson. 1996. The Sounds of the World's Languages. London: Blackwell.

Lindau, Mona. 1985. "The Story of /r/." Phonetic Linguistics: Essays in Honor of Peter Ladefoged ed. by Victoria A. Fromkin, 157-168. Orlando: Academic Press.

Lipski, John M. 1990/1991. "Metathesis as Template Matching: A Case Study from Spanish”. Folia Linguistica Historica 11.89-104 (= 12 (1991) 127-45).

Martinet, André. 1964. Economie des changements phonétiques: traité de phonologie diachronique. Bern: Francke.

McMahon, April. 2000. Change, Chance, and Optimality. Oxford: Oxford University Press.

Ohala, John J. 1993. "The Phonetics of Sound Change”. Historical Linguistics: Problems and Perspectives ed. by Charles Jones, 237-278. London: Longman.

Peperkamp, Sharon \& Emmanuel Dupoux. 2003. "Reinterpreting Loanword Adaptations: The Role of Perception". Proceedings of the $15^{\text {th }}$ International Conference of Phonetic Sciences, 367-370.

Prince, Alan \& Paul Smolensky. 1993. "Optimality Theory: Constraint Interaction in Generative Grammar”. Ms., Rutgers University \& University of Colorado.

Russell Webb, Eric. 2002. The Relational /R/: Three case studies of rhotic integrity and variation. Ph.D. dissertation, University of Texas, Austin.

---------. 2004. "Explanatory Adequacy in Phonology: A Deductive Approach to /R/”. Linguistica Atlantica 25:77-94.

---------. In press-a. "Formalizing Creole Sound Change: An Optimality Theoretic Account”. Journal of Pidgin and Creole Linguistics.

---------. In press-b. "Lenition, Elision, Epenthesis and the Variable Nature of French /b/". VaRiations: Contemporary Research on Rhotics ed. by Hans van de Velde, Willem Zonneveld \& Didier Demoulin. Amsterdam \& Philadelphia: John Benjamins.

Steriade, Donca. 1990. "Gestures and Autosegments: Comments on Browman and Goldstein's Paper”. Papers in Laboratory Phonology I: Between the Grammar and Physics of Speech ed. by Mary Beckman \& John Kingston, 382-397. Cambridge: Cambridge University Press.

Tranel, Bernard. 1987. The Sounds of French. Cambridge: Cambridge University Press.

Walker, Douglas C. 2001. French Sound Structure. Calgary: University of Calgary Press. 
Walsh-Dickey, Laura. 1997. The Phonology of Liquids. Ph.D. dissertation, University of Massachusetts, Amherst.

Wiese, Richard. 2001. "The Phonology of /r/." Distinctive Feature Theory ed. by Tracy Alan Hall, 335-368. Berlin: Mouton de Gruyter. 